\title{
Associations between birth weight, early childhood weight gain and adult lung function
}

\author{
R J Hancox, ${ }^{1}$ R Poulton, ${ }^{1}$ J M Greene, ${ }^{2}$ C R McLachlan, ${ }^{1}$ M S Pearce, ${ }^{3}$ M R Sears ${ }^{2}$
}

\begin{abstract}
- Additional tables are published online only at http:// thorax.bmj.com/content/vol64/ issue 3

${ }^{1}$ Dunedin Multidisciplinary Health and Development Research Unit, Dunedin School of Medicine, University of Otago, Dunedin, New Zealand:

${ }^{2}$ Firestone Institute for Respiratory Health, St Joseph's Healthcare and Department of Medicine, McMaster University, Hamilton, Ontario, Canada; ${ }^{3}$ School of Clinical Medical Sciences and Institute of Health and Society, Newcastle University, UK
\end{abstract}

Correspondence to: Dr R J Hancox, Dunedin Multidisciplinary Health and Development Research Unit, Dunedin School of Medicine, University of Otago, Dunedin New Zealand; bob.hancox@ otago.ac.nz

\section{R McLachlan is deceased.}

Received 12 July 2008 Accepted 24 October 2008 Published Online First 3 December 2008

\begin{abstract}
Background: Low birth weight is associated with lower values for spirometry in adults but it is not known if birth weight influences other measures of pulmonary function. It is also unclear whether postnatal growth affects adult lung function. The associations between birth weight, postnatal growth and adult lung function were assessed in an unselected birth cohort of 1037 children.
\end{abstract}

Methods: Birth weight, weight gain between birth and age 3 years, and lung function at age 32 years were measured. Analyses were adjusted for adult height and sex and further adjusted for multiple other potential confounding factors.

Results: Birth weight was positively correlated with spirometric (forced expiratory volume in $1 \mathrm{~s}$ and forced vital capacity) and plethysmographic (total lung capacity and functional residual capacity) lung function and with lung diffusing capacity. These associations persisted after adjustment for confounding factors including adult weight, exposure to cigarette smoke in utero and during childhood, personal smoking, socioeconomic status, asthma and gestational age. Weight gain between birth and age 3 years was also positively associated with lung diffusing capacity, and with higher values of lung volumes in men after adjustment for covariates. Neither birth weight nor postnatal weight gain was associated with airflow obstruction.

Conclusions: Low birth weight and lower weight gain in early childhood are associated with modest reductions in adult lung function across a broad range of measures of lung volumes and with lower diffusing capacity. These findings are independent of a number of potential confounding factors and support the hypothesis that fetal and infant growth is a determinant of adult lung function.

The "fetal origins" hypothesis proposes that impairment of intrauterine growth may have long term consequences for physiological function and risk for adult disease. ${ }^{1}$ With respect to respiratory health, a number of studies have reported an association between low birth weight and lower lung function in adulthood. ${ }^{2-6}$ Although not all studies have observed this association, ${ }^{78}$ a recent meta-analysis and subsequent reports support a modest positive association between birth weight and adult forced expiratory volume in $1 \mathrm{~s}$ $\left(\mathrm{FEV}_{1}\right)^{9-11}$ These findings support the hypothesis that intrauterine growth is a critical time for lung development and a determinant of eventual lung function.

Whether fetal growth influences other aspects of respiratory function is not known because most studies have relied on spirometry to assess adult lung function. Studies of other measures of lung function have been small and restricted to patients with severe prematurity who have developed bronchopulmonary dysplasia. ${ }^{12}$ Even for spirometric outcomes, it remains uncertain whether low birth weight is primarily associated with an obstructive or restrictive pattern of reduced lung function in adulthood. Although several studies have found parallel reductions in both $\mathrm{FEV}_{1}$ and forced vital capacity (FVC) indicating restriction, ${ }^{51011} 13$ other studies have not found a significant effect on FVC, suggesting an obstructive defect. ${ }^{2}$ One potential reason for the inconsistency between studies is that some have been retrospective while others have been unable to control for factors that may confound or mediate the association between birth weight and adult lung function. For example, lower socioeconomic status and maternal smoking may cause both low birth weight and impaired postnatal lung growth. ${ }^{14} 15$

There is less information on whether postnatal growth influences adult lung function. One study found that adult $\mathrm{FEV}_{1}$ and FVC were positively associated with weight gain in the first year of life although the effect on $\mathrm{FEV}_{1}$ was not statistically significant in men. ${ }^{10}$ However, another cohort found that growth in the first year of life was not related to adult lung function. ${ }^{16}$ Other studies have reported that greater postnatal weight gain is associated with lower lung function in infancy. ${ }^{17} 18$

To our knowledge, there have been no studies of the association between fetal development and a comprehensive assessment of adult lung function in a population based sample. There is good reason to postulate that the impact of fetal growth on respiratory physiology may vary because the pattern of growth differs for different lung structures: whereas the number of conducting airways is normally complete at birth, $85 \%$ of alveoli are believed to develop postnatally. ${ }^{19} \mathrm{We}$ explored the association between birth weight, postnatal growth and adult lung function in a prospective population based cohort followed to age 32 years.

\section{METHODS}

Study members were born in Dunedin, New Zealand, between April 1972 and March 1973. ${ }^{20} 21$ A total of 1037 children (91\% of eligible births; $52 \%$ male) participated in the first follow-up assessment at age 3 years, constituting the base sample for the remainder of the study. This analysis explores the association between birth weight, weight change between birth and age 3 years, and lung function at age 32 years, which was measured in $94 \%$ of living study members (953/1015). Study members were mostly of New Zealand/European ethnicity. 
Table 1 Birth characteristics of the study members

\begin{tabular}{lrlr}
\hline $\begin{array}{l}\text { Birth weight } \\
\text { (kg) }\end{array}$ & No & $\begin{array}{l}\text { Gestational age } \\
\text { (weeks) }\end{array}$ & No \\
\hline$<1.5$ & 3 & $<32$ & 1 \\
$1.5-2.49$ & 47 & $32-36$ & 40 \\
$2.5-3.49$ & 551 & $37-42$ & 774 \\
$3.5-4.49$ & 423 & $>42$ & 100 \\
$\geqslant 4.5$ & 13 & Unknown & 122 \\
\hline
\end{tabular}

At age 32 years, 6\% identified themselves as Maori. Few study members identified with other ethnicities. The Otago Ethics Committee approved the study. Written informed consent was obtained.

Birth weight was measured for all study members. Gestational age was calculated from the date of the last menstrual period when this was recalled with confidence $(n=915)$. Ninety-seven per cent of children were reassessed within 1 month of their third birthday, but 31 were assessed during the second month after their birthday. Weight at age 3 years was available for 951 study members. Childhood socioeconomic status was calculated as the average of the higher socioeconomic status level of either parent, based on the education and income associated with their occupation, assessed repeatedly from the study member's birth through to age 15 years. $^{22} 23$

Information obtained about respiratory health throughout the life course was updated at age 32 years, including questions from the American Thoracic Society and the European Community Respiratory Health Survey questionnaires. ${ }^{24} 25$ Current asthma is defined as a diagnosis of asthma with episodes of asthma, wheezing or asthma medication use in the previous year. Cumulative smoking was calculated as the number of pack years cigarettes smoked up to age 32 years (20 cigarettes per day for 1 year $=1$ pack year). Smoking history for both parents/guardians was obtained from the adult attending with the study member at ages 7,9 and 11 years and from the study members themselves at age 13 years. ${ }^{26}$ Maternal smoking during pregnancy was recorded retrospectively at the age 9 assessment and this information was available for 777 study members.

Height and weight were measured in light clothing without shoes. Spirometry (FEV 1 and FVC), static lung volumes (total lung capacity (TLC), functional residual capacity (FRC), residual volume $(\mathrm{RV})$ ) and single breath diffusing capacity for carbon monoxide (TlCO) and alveolar volume by methane

Table 2 Mean lung function values at age 32 years

\begin{tabular}{|c|c|c|c|c|c|c|}
\hline & \multicolumn{3}{|c|}{ Women } & \multicolumn{3}{|l|}{ Men } \\
\hline & No & Mean & SD & No & Mean & SD \\
\hline $\mathrm{FEV}_{1}(\mathrm{I})$ & 435 & 3.34 & 0.46 & 486 & 4.43 & 0.64 \\
\hline FVC (I) & 435 & 4.19 & 0.57 & 486 & 5.79 & 0.78 \\
\hline $\mathrm{FEV}_{1} / \mathrm{FVC}(\%)$ & 435 & 79.8 & 6.19 & 486 & 76.7 & 6.83 \\
\hline TLC (I) & 419 & 5.59 & 0.73 & 465 & 7.50 & 0.96 \\
\hline FRC (I) & 419 & 2.81 & 0.61 & 466 & 3.46 & 0.78 \\
\hline RV (I) & 419 & 1.37 & 0.33 & 465 & 1.65 & 0.42 \\
\hline TIco $(\mathrm{ml} / \mathrm{min} / \mathrm{mm} \mathrm{Hg})$ & 422 & 24.1 & 3.74 & 473 & 34.3 & 5.71 \\
\hline TIco/ $\mathrm{Va}(\mathrm{ml} / \mathrm{min} / \mathrm{mm} \mathrm{Hg} / \mathrm{l})$ & 422 & 4.66 & 0.69 & 473 & 4.84 & 0.76 \\
\hline Va (I) & 422 & 5.21 & 0.71 & 473 & 7.14 & 0.95 \\
\hline
\end{tabular}

Pregnant women were excluded.

$\mathrm{FEV}_{1}$, forced expiratory volume in $1 \mathrm{~s}$; FRC, functional residual capacity; FVC, forced vital capacity; RV, residual volume; TLC, total lung capacity; TICo, single breath diffusing capacity for carbon monoxide; Va, alveolar volume. dilution ( $\mathrm{Va}$ ) were measured to American Thoracic Society standards ${ }^{27-29}$ using a Sensormedics 6200 plethysmograph with Vmax version $4.3 \mathrm{~b}$ software (Yorba Linda, California, USA). A portable spirometer (Spiropro, Sensormedics, Yorba Linda) was used to test those who refused to sit in the plethysmograph or were unable to attend the research unit $(n=27)$. All tests were reviewed by a senior technician to ensure only acceptable and reproducible results were entered for analysis. Equipment was calibrated daily, and weekly quality control measures were obtained to ensure accuracy and precision of the test equipment.

Haemoglobin was measured on a Sysmex XE2100 automated haematology analyser (Sysmex Corporation, Japan). Exhaled carbon monoxide was measured twice using a Micro CO monitor, (Micromedical, UK) and the average was recorded.

Associations between birth weight and adult lung function measurements were analysed by multiple linear regression using lung function as the dependent variable and birth weight as the main predictor (independent variable). In addition to the lung function variables listed above, $\mathrm{FEV}_{1} / \mathrm{FVC}$ and $\mathrm{Tlco} / \mathrm{Va}$ ratios were analysed as indicators of airflow obstruction and the diffusing capacity per unit alveolar volume, respectively. Initial analyses of the association between birth weight and adult lung function adjusted for adult height and sex. Analyses of Tlco and Tlco/Va additionally adjusted for haemoglobin and exhaled carbon monoxide. Analyses also tested sex $\times$ birth weight interaction terms to assess if the association between birth weight and adult lung function differed for males and females. These analyses were repeated using weight change between birth and age 3 years as the main predictor.

Further analyses included both birth weight and weight change between birth and age 3 years as the main predictors. These analyses also adjusted for a number of potential covariates: gestational age, maternal smoking during pregnancy, parental smoking during childhood, personal smoking up to age 32 years in pack years, childhood socioeconomic status, current asthma at age 32 years and body weight at age 32 years. Interaction terms between birth weight and weight change up to age 3 years were calculated to assess whether the influence of either predictor depended on the other (eg, low birth associated with greater postnatal weight gain).

Women who were pregnant at the time of the age 32 assessment $(n=31)$ were excluded from all analyses. Visual inspection of the residuals from the regression models identified one clear outlier. This individual was excluded from the analyses. Analyses were performed using Stata 10.0 (StataCorp, College Station Texas, USA).

\section{RESULTS}

The birth characteristics of the study members are shown in table 1 . Birth weight correlated with gestational age $(r=0.46$, $\mathrm{p}<0.0001$ ) and tended to be higher in boys (mean (SD) 3.43 (0.53) vs $3.31(0.51) \mathrm{kg}$ in girls; $p<0.001)$. Birth weight also correlated with weight at age 32 years (sex adjusted correlation: $\mathrm{r}=0.17, \mathrm{p}<0.001)$. Weight gain between birth and age 3 years was greater in boys than girls (means (SD) 11.6 (1.6) and 11.1 $(1.5) \mathrm{kg}$, respectively; $\mathrm{p}<0.0001)$ and was weakly correlated with birth weight (sex adjusted correlation: $r=0.06, p=0.047$ ). Weight gain between birth and age 3 years also correlated with adult weight (sex adjusted correlation: $r=0.31, p<0.0001$ ). Mean values for the lung function tests are shown in table 2.

Higher birth weights tended to be associated with higher spirometric and plethysmographic lung volumes in adulthood (table 3). These trends were not statistically significant in the 
Table 3 Regression analyses of age 32 lung function on birth weight

\begin{tabular}{|c|c|c|c|c|c|c|}
\hline & \multicolumn{3}{|c|}{ Adjusted for sex and height } & \multicolumn{3}{|c|}{ Fully adjusted } \\
\hline & No & Coeff $(95 \%$ CI) & p Value & No & Coeff $(95 \%$ CI) & p Value \\
\hline $\mathrm{FEV}_{1}(\mathrm{ml})$ & 921 & $55.9(-8$ to 120$)$ & 0.087 & 588 & 100.1 (14 to 186$)$ & 0.023 \\
\hline $\mathrm{FVC}(\mathrm{ml})$ & 921 & $64.7(-10$ to 139$)$ & 0.088 & 588 & 118.6 (15 to 223 ) & 0.026 \\
\hline $\mathrm{FEV}_{1} / \mathrm{FVC}(\%)$ & 921 & $0.01(-0.82$ to 0.84$)$ & 0.974 & 588 & $0.00(-1.16$ to 1.17$)$ & 0.995 \\
\hline TLC (ml) & 884 & $81.6(-11$ to 174$)$ & 0.084 & 570 & 151.0 (27 to 275 ) & 0.017 \\
\hline FRC (ml) & 885 & $56.7(-29$ to 143$)$ & 0.196 & 571 & 134.5 (41 to 228 ) & 0.005 \\
\hline $\mathrm{RV}(\mathrm{ml})$ & 884 & $6.0(-42$ to 54$)$ & 0.805 & 570 & 40.1 (-23 to 104$)$ & 0.215 \\
\hline Tlco $(\mathrm{ml} / \mathrm{min} / \mathrm{mm} \mathrm{Hg})$ & 842 & $0.97(0.42$ to 1.53$)$ & 0.001 & 539 & $1.19(0.41$ to 1.97$)$ & 0.003 \\
\hline Tlco $/ \mathrm{Va}(\mathrm{ml} / \mathrm{min} / \mathrm{mm} \mathrm{Hg} / \mathrm{l})$ & 842 & $0.10(0.01$ to 0.19$)$ & 0.025 & 539 & $0.11(-0.01$ to 0.23$)$ & 0.077 \\
\hline Va (ml) & 895 & $50.8(-41$ to 143$)$ & 0.277 & 576 & $95.8(-29$ to 221$)$ & 0.133 \\
\hline
\end{tabular}

All analyses adjust for sex and (except for $\mathrm{FEV}_{1} / \mathrm{FVC}$ ) height at age 32 years. All analyses of TIco and TIco/Va adjust for exhaled carbon monoxide and blood haemoglobin. Analyses in the fully adjusted models also adjust for weight gain between birth and age 3 years, gestational age, maternal smoking during pregnancy, parental smoking during childhood, personal smoking history to age 32 years, childhood socioeconomic status, current asthma at age 32 years and weight at age 32 years. Coefficients represent the difference in lung function associated with a $1 \mathrm{~kg}$ difference in birth weight.

$\mathrm{FEV}_{1}$, forced expiratory volume in $1 \mathrm{~s}$; FRC, functional residual capacity; FVC, forced vital capacity; RV, residual volume; TLC, total lung capacity; TIco, single breath diffusing capacity for carbon monoxide; Va, alveolar volume.

sex and height adjusted models but were significant in the fully adjusted analyses. Birth weight was also significantly associated with diffusing capacity (Tlco). Similar trends were found for diffusing capacity adjusted for alveolar volume (Tlco/Va) although this was not statistically significant in the fully adjusted model. Sex $\times$ birth weight interaction terms were not significant with the exception of Tlco $(p=0.023)$. The association between birth weight and Tlco was stronger in males (coefficient (95\% CI) 1.47 (0.60 to 2.34); $p=0.001$ ) than in females $(0.36$ ( -0.28 to 1.00$) ; p=0.27$ ) after adjustment for height, haemoglobin and exhaled carbon monoxide. This sex interaction was not apparent in the fully adjusted model when the coefficients were similar for males and females $(1.19)(-0.08$ to 2.46 ) and 1.13 (0.22 to 2.05), respectively).

Weight gain between birth and 3 years was not significantly associated with any of the spirometric or plethysmographic lung volumes in the sex and height adjusted analyses; however, there was a trend to lower FRC values with greater weight gain (table 4). Greater weight gain was associated with higher values for adult FRC in the fully adjusted model with trends to higher TLC and RV (table 4). Weight gain between birth and 3 years was associated with higher values for Tlco but not Tlco/Va. There were significant interactions between sex and weight gain for $\mathrm{FVC}$ and $\mathrm{Va}(\mathrm{p}=0.015$ and 0.047 , respectively). In females, there were no associations between weight gain and either FVC or Va values in any of the analyses. In males, there were trends to positive associations in the sex and height adjusted models which were statistically significant in the fully adjusted models (coefficient $=67.0$ (14 to $120 ; p=0.013$ ) for FVC and 79.2 (16 to 142; $p=0.014$ ) for $\mathrm{Va}$ ).

None of the birth weight $\times$ weight gain interaction terms were significant in any of the analyses, indicating that the associations between birth weight and postnatal weight gain with adult lung function were not contingent upon each other.

Birth weight was highly correlated with other measures of birth size including length $(r=0.81)$, head circumference $(r=0.78)$, body mass index (BMI) $(r=0.86)$ and ponderal index $(r=0.54)$ (all $p$ values $<0.001)$. Birth weight was an equivalent or better predictor of adult lung function than either length or head circumference but the composite measures of height and length (BMI and ponderal index) were slightly better predictors of some measures of adult lung function (see table 1 online). Similarly, weight gain between birth and age 3 years correlated with change in height $(r=0.60, p<0.001)$ and change in BMI $(r=0.59, p<0.001)$. Change in BMI was a similar predictor of adult lung function to change in weight (see table 2 online) whereas change in height did not predict adult lung function.

Table 4 Regression analyses of age 32 lung function on weight gain between birth and age 3 years

\begin{tabular}{|c|c|c|c|c|c|c|}
\hline & \multicolumn{3}{|c|}{ Adjusted for sex and height } & \multicolumn{3}{|c|}{ Fully adjusted } \\
\hline & No & Coeff (95\% CI) & p Value & No & Coeff $(95 \% \mathrm{CI})$ & p Value \\
\hline $\mathrm{FEV}_{1}(\mathrm{ml})$ & 848 & $2.0(-22$ to 26$)$ & 0.868 & 588 & $11.1(-17$ to 39$)$ & 0.441 \\
\hline FVC (ml) & 848 & $15.8(-12$ to 44$)$ & 0.266 & 588 & $22.6(-12$ to 57$)$ & 0.194 \\
\hline $\mathrm{FEV}_{1} / \mathrm{FVC}(\%)$ & 848 & $-0.18(-0.47$ to 0.12$)$ & 0.238 & 588 & $-0.11(-0.48$ to 0.26$)$ & 0.562 \\
\hline TLC (ml) & 816 & $16.8(-18$ to 51$)$ & 0.340 & 570 & $38.8(-2$ to 80$)$ & 0.062 \\
\hline FRC (ml) & 817 & $-30.7(-63$ to 1$)$ & 0.060 & 571 & 38.8 (8 to 70$)$ & 0.014 \\
\hline RV (ml) & 816 & $3.4(-14$ to 21$)$ & 0.703 & 570 & $20.2(-0.5$ to 41$)$ & 0.057 \\
\hline Tlco $(\mathrm{ml} / \mathrm{min} / \mathrm{mm} \mathrm{Hg})$ & 775 & $0.22(0.01$ to 0.43$)$ & 0.037 & 539 & $0.36(0.10$ to 0.63$)$ & 0.006 \\
\hline Tlco $/ \mathrm{Va}(\mathrm{ml} / \mathrm{min} / \mathrm{mm} \mathrm{Hg} / \mathrm{l})$ & 775 & $0.01(-0.02$ to 0.05$)$ & 0.425 & 539 & $0.03(-0.01$ to 0.07$)$ & 0.144 \\
\hline Va (ml) & 825 & $22.1(-12$ to 56$)$ & 0.206 & 576 & $34.3(-7$ to 75$)$ & 0.102 \\
\hline
\end{tabular}

All analyses adjust for sex and (except for $\mathrm{FEV}_{1} / \mathrm{FVC}$ ) height at age 32 years. All analyses of TIco and TIco/Va adjust for exhaled carbon monoxide and blood haemoglobin. Analyses in the fully adjusted models also adjust for birth weight, gestational age, maternal smoking during pregnancy, parental smoking during childhood, personal smoking history to age 32 years, childhood socioeconomic status, current asthma at age 32 years and weight at age 32 years. Coefficients represent the difference in lung function associated with a $1 \mathrm{~kg}$ difference in weight gain.

$\mathrm{FEV}_{1}$, forced expiratory volume in $1 \mathrm{~s}$; FRC, functional residual capacity; FVC, forced vital capacity; RV, residual volume; TLC, total lung capacity; TIco, single breath diffusing capacity for carbon monoxide; Va, alveolar volume. 


\section{DISCUSSION}

In this population based cohort, higher birth weight was associated with higher values of adult lung function. This association was not only found for spirometric lung volumes, as previously reported, but also for measures of static lung volume measured by plethysmography and for lung diffusing capacity. These findings support the hypothesis that impaired intrauterine growth may have long term consequences for lung development.

The associations between lower birth weight and adult lung function were stronger in the fully adjusted analysis which included adjustment for adult weight. This indicates that the associations between birth weight and lung function were not mediated by the correlation between birth weight and subsequent weight gain to adulthood. However, an alternative interpretation is that it is the change between birth and adult weight which is the primary predictor-in other words, "centile crossing" as low birth weight babies catch up growth with their peers. ${ }^{30}$ This seems an unlikely explanation for our findings. Although birth weight was weakly correlated with weight gain between birth and age 3 years, the associations between birth weight and lung function were independent of this. There were no significant interactions between birth weight and either postnatal weight gain or adult weight for any of the lung function outcomes, indicating that the associations between birth weight and adult lung function were not contingent on subsequent growth. Finally, when the fully adjusted analyses were repeated without adjustment for adult weight, a broadly similar pattern of findings was observed (see table 3 online).

The adjusted analyses also indicate that the associations between birth weight and lung function were independent of a number of potential covariates which may have confounded or mediated the association. For example, low gestational age, ${ }^{12}$ lower socioeconomic status ${ }^{14}$ and maternal smoking ${ }^{31}$ have been associated with both low birth weight and impaired lung development. In fact, in our analyses, none of these was a significant independent predictor of adult lung function. Analyses excluding these covariates showed a similar pattern of findings (see table 4 online).

Interpreting the association between postnatal growth and adult lung function is more difficult. The finding that postnatal weight gain predicted adult diffusing capacity is in keeping with the fact that most alveoli are formed during this time. ${ }^{19}$ Weight gain between birth and age 3 years was also associated with higher values for static lung volumes in the fully adjusted analyses, which is consistent with this being the main stage of alveolar development. However, these associations were only apparent if the analyses adjusted for adult body weight (see table 4, and online table 3). This suggests that these associations may be due to confounding by the association between weight gain up to age 3 years and body weight at age 32 years which was inversely associated with all dynamic and static measures of lung volumes. Unfortunately, we do not have measurements of weight earlier in infancy to further clarify the relation between postnatal growth and adult lung volumes.

To our knowledge, this is the first report of the association between birth weight, weight gain in early childhood and a comprehensive assessment of adult respiratory function in a population based cohort. Previous reports have been restricted to small numbers of severely premature babies at risk of bronchopulmonary dysplasia. We found that although birth weight correlated with gestational age, the associations were independent of this indicating that the effects on lung function were not due to premature birth. Excluding the small number of babies born before 37 weeks gestation made little difference to the associations between birth weight and adult lung function (data not shown).

We found little evidence for an association between either birth weight or weight gain in the first 3 years and the $\mathrm{FEV}_{1}$ / FVC ratio. Although an inverse association between weight gain and the $\mathrm{FEV}_{1} / \mathrm{FVC}$ ratio was identified in men in the fully adjusted analysis, this was because weight gain was associated with higher values for FVC rather than lower values for FEV 1 (data not shown). Our findings are consistent with other reports $^{310}$ and suggest that the impairment in lung function associated with a low birth weight is compatible with a restrictive defect rather than airways obstruction. This is also true for the pattern of changes associated with lower postnatal growth in the fully adjusted analyses.

Birth weight has been used as the measure of fetal growth in many studies of the fetal origins hypothesis, including most of those analysing the association with adult lung function. Possibly this is because birth weight is the most available measure in many datasets. One cohort used multiple measures including BMI at birth and 1 year to predict adult spirometry. ${ }^{16}$ In keeping with this report, we found birth weight to be an equivalent or better predictor of adult lung function than some other measures of birth size, including length. Analyses using BMI at birth and change in BMI between birth and age 3 years were similar to the birth weight and weight change analyses but in some cases birth BMI appeared to be a better predictor (tables 1 and 2 online).

The study has a number of strengths. It is a large population based cohort with a high rate of follow-up. Lung function was measured by experienced technicians with rigorous quality control measures. Information about birth weight and other perinatal factors, smoking, socioeconomic status and asthma were obtained prospectively. Even though missing data for some of the covariates reduced the numbers available for the fully adjusted analyses, the proportion of participants available for these analyses compares favourably with other studies. ${ }^{2-5} 71011$ Moreover, there were no significant differences in birth weight, postnatal weight gain or adult lung function between those with and without missing covariate data, and restricting the sex and height adjusted analyses to those with full covariate data provided similar results (not shown).

A limitation of this study is our inability to adjust for other factors that may confound or mediate the association between low birth weight and reduced lung function. For example, we have little information on lower respiratory tract infections in early life. Low birth weight babies may be more susceptible to such infections and these could impair lung development. ${ }^{8} \mathrm{We}$ have no information on maternal diet during pregnancy. We also have little information on childhood diet although adjusting for breastfeeding ${ }^{32}$ made no material difference to any of the analyses (data not shown).

Taken together, these findings lend support to the hypothesis that eventual adult lung function is partly determined by fetal growth, and to a lesser extent may be determined by infant growth. The size of these effects seems modest-based on the adjusted analyses (table 3), a $1 \mathrm{~kg}(30 \%)$ increase in birth weight is associated with increases in lung volumes and diffusing capacity of between $2 \%$ and $4 \%$. The clinical and public health significance of these differences is uncertain. However, birth weight is, at best, only a crude measure of fetal development and hence these analyses may underestimate its influence on adult lung function. It is becoming increasingly apparent that lung function has an impact on cardiovascular and all-cause 
mortality as well as on respiratory outcomes. ${ }^{33-35}$ It remains to be seen whether attempts to enhance interuterine and postnatal growth can have a longlasting influence on lung development.

Acknowledgements: We are grateful to the study members and families of the Dunedin study for their continued support. We also thank Dr Phil A Silva, the study founder. We wish to dedicate this article to the memory of Christene McLachlan whose dedication and meticulous attention to detail was fundamental to the respiratory assessment. She was involved in the conception of this report but unfortunately did not see its completion.

Funding: The Dunedin Multidisciplinary Health and Development Research Unit is funded by the Health Research Council of New Zealand. MRS holds the AstraZeneca Chair in Respiratory Epidemiology at McMaster University.

Competing interests: None.

Ethics approval: The Otago Ethics Committee approved the study.

\section{REFERENCES}

1. Barker DJ. The foetal and infant origins of inequalities in health in Britain. J Public Health Med 1991:13:64-8.

2. Barker DJ, Godfrey KM, Fall C, et al. Relation of birth weight and childhood respiratory infection to adult lung function and death from chronic obstructive airways disease. BMJ 1991;303:671-5.

3. Stein CE, Kumaran K, Fall CH, et al. Relation of fetal growth to adult lung function in south India. Thorax 1997;52:895-9.

4. Lopuhaa CE, Roseboom TJ, Osmond C, et al. Atopy, lung function, and obstructive airways disease after prenatal exposure to famine. Thorax 2000;55:555-61.

5. Boezen HM, Vonk JM, van Aalderen WMC, et al. Perinatal predictors of respiratory symptoms and lung function at a young adult age. Eur Respir J 2002;20:383-90.

6. Tennant PWG, Gibson GJ, Pearce MS. Lifecourse predictors of adult respiratory function: results from the Newcastle Thousand Families Study. Thorax 2008;63:823-30.

7. Laerum BN, Svanes C, Gulsvik A, et al. Is birth weight related to lung function and asthma symptoms in Nordic-Baltic adults? Respir Med 2004;98:611-18.

8. Shaheen So, Sterne JA, Tucker JS, et al. Birth weight, childhood lower respiratory tract infection, and adult lung function. Thorax 1998;53:549-53.

9. Lawlor DA, Ebrahim S, Davey Smith G. Association of birth weight with adult lung function: findings from the British Women's Heart and Health Study and a metaanalysis. Thorax 2005; 60:851-8.

10. Canoy D, Pekkanen J. Elliott $P$, et al. Early growth and adult respiratory function in men and women followed from the fetal period to adulthood. Thorax 2007;62:396-402.

11. Orfei L, Strachan DP, Rudnicka AR, et al. Early influences on adult lung function in two national British birth cohorts. Arch Dis Child 2008;93:570-4.

12. Vrijlandt EJLE, Gerritsen J, Boezen HM, et al. Lung function and exercise capacity in young adults born prematurely. Am J Respir Crit Care Med 2006;173:890-6.

13. Edwards CA, Osman LM, Godden DJ, et al. Relationship between birth weight and adult lung function: controlling for maternal factors. Thorax 2003;58:1061-5.

14. Hegewald MJ, Crapo RO. Socioeconomic status and lung function. Chest 2007:132:1608-14.
15. Hofhuis W, de Jongste JC, Merkus PJ. Adverse health effects of prenatal and postnatal tobacco smoke exposure on children. Arch Dis Child 2003;88:1086-90

16. Ubilla C, Bustos $\mathrm{P}$, Amigo $\mathrm{H}$, et al. Nutritional status, especially body mass index from birth to adulthood and lung function in young adulthood. Ann Hum Biol 2008;35:322-33.

17. Lucas JS, Inskip HM, Godfrey KM, et al. Small size at birth and greater postnatal weight gain: relationships to diminished infant lung function. Am J Respir Crit Care Med 2004;170:534-40.

18. Turner S, Zhang G, Young S, et al. Associations between postnatal weight gain, change in postnatal pulmonary function, formula feeding and early asthma. Thorax 2008:63:234-9

19. Merkus PJ, ten Have-Opbroek AA, Quanjer PH. Human lung growth: a review. Pediatr Pulmonol 1996;21:383-97.

20. Silva PA, Stanton WR. From child to adult: The Dunedin Multidisciplinary Health and Development Study. Auckland: Oxford University Press, 1996.

21. Sears MR, Greene JM, Willan AR, et al. A longitudinal, population-based, cohort study of childhood asthma followed to adulthood. N Engl J Med 2003;349:1414-22.

22. Elley WB, Irving JC. The Elley-Irving socio-economic index 1981 census revision. N Z J Educ Stud 1985;29:115-28.

23. Hancox RJ, Milne BJ, Taylor DR, et al. Relationship between socioeconomic status and asthma: a longitudinal cohort study. Thorax 2004;59:376-80.

24. Ferris BG. Epidemiology Standardization Project (American Thoracic Society). Am Rev Respir Dis 1978;118:1-120.

25. Burney $\mathbf{P}$, Chinn S. Developing a new questionnaire for measuring the prevalence and distribution of asthma. Chest 1987:91 (6 Suppl):79S-83.

26. Hancox RJ, Welch D, Poulton R, et al. Cigarette smoking and allergic sensitization: a 32-year population-based cohort study. J Allergy Clin Immunol 2008;121:38-42 e3.

27. American Thoracic Society. Standardization of spirometry, 1994 update. Am J Respir Crit Care Med 1995;152:1107-36.

28. American Thoracic Society. Single-breath carbon monoxide diffusing capacity (transfer factor). Recommendations for a standard technique-1995 update. Am J Respir Crit Care Med 1995;152:2185-98.

29. Coates AL, Peslin R, Rodenstein D, et al. Measurement of lung volumes by plethysmography. Eur Respir J 1997;10:1415-27.

30. Lucas A, Fewtrell MS, Cole TJ. Fetal origins of adult disease-the hypothesis revisited. BMJ 1999;319:245-9.

31. Cook DG, Strachan DP, Carey IM. Health effects of passive smoking. 9. Parental smoking and spirometric indices in children. Thorax 1998;53:884-93.

32. Sears MR, Greene JM, Willan AR, et al. Long-term relation between breastfeeding and development of atopy and asthma in children and young adults: a longitudinal study. Lancet 2002;360:901-7.

33. Hole DJ, Watt GC, Davey-Smith G, et al. Impaired lung function and mortality risk in men and women: findings from the Renfrew and Paisley prospective population study. BMJ 1996;313:711-15.

34. Schunemann HJ, Dorn J, Grant BJ, et al. Pulmonary function is a long-term predictor of mortality in the general population: 29-year follow-up of the Buffalo Health Study. Chest 2000;118:656-64.

35. Hancox RJ, Poulton R, Greene JM, et al. Systemic inflammation and lung function in young adults. Thorax 2007;62:1064-8. 